\title{
Purification of Sodium Chloride and Potassium Chloride for Use in Electrochemical Work, and the Determination of Small Amounts of Bromide
}

\author{
By Gladys D. Pinching and Roger G. Bates
}

\begin{abstract}
The effects of small amounts of dissolved impurities on the potentials of silver-silverhalide electrodes immersed in solutions of alkali halides were studied. Traces of bromide exert disturbing effects on the potential of the silver-silver-chloride electrode. A convenient method for determining small amounts of bromide in the presence of chlorides and a satisfactory means of purifying sodium and potassium chlorides for precise electrochemical work are outlined. The procedure involves treatment of a saturated solution of the salt with chlorine, two successive precipitations with hydrogen chloride, and fusion of the airdried product. A method for diminishing hydrolysis of the salts during fusion is described.
\end{abstract}

\section{Effect of Dissolved Impurities on the Potentials of Silver- Silver-Halide Electrodes Immersed in Solutions of Alkali Halides}

Small amounts of bromide are known to exert a large effect on the potentials of the saturated calomel electrod $3[1]^{1}$ and the silver-silver-chloride electrode $[2,3]$. Sodium chloride and potassium chloride, sufficiently pure for many physicochemical purposes, may, because of the presence of small amounts of bromide, be quite unsuitable for the most precise electrometric work. A series of emf measurements was made to obtain quantitative information regarding this effect and to ascertain whether some of the other common impurities have a similar disturbing influence.

\section{Experimental Procedures}

Cell vessels of a modified $\mathrm{H}$-type were used The two arms of each cell were separated by a stopcock with a 5 -mm bore. Each arm could be filled and emptied by use of pure hydrogen without the introduction of air. Two electrodes were used in each arm of the cell.

Silver-silver-chloride electrodes of the thermalelectrolytic type [4, type 2] were used. Silver-

\footnotetext{
1 Figures in brackets indicate the literature references at the end of this paper.
}

\section{Contents}

I. Effect of dissolved impurities on the potentials of silver-silver-halide electrodes immersed in solutions of alkali halides _..._._. _ _ _ _ _ _ 311

1. Experimental procedures_........... 311

2. Calculation of the normal effect of impurities............................. 313

3. Anomalous effect of bromide on the silver-silver-chloride electrode........ 314

II. Determination of bromide in the presence of chloride_._.

III. Methods of purifying sodium chloride and potassium chloride.... 316

1. Recrystallization from water

2. Precipitation with ethyl alcohol_..._. 316

3. Precipitation with hydrogen chloride_. 316

4. Treatment with chlorine _._._._. _ 317

IV. Detection and removal of iodide_... _._._. 317

V. Fusion of sodium chloride and potassium chloride. . . . 317

VI. Recommended procedures_........ 318

VII. References_... 
silver-bromide electrodes were made as outlined by Keston [5], except that the mixture of silver oxide and silver bromate was decomposed at $550^{\circ} \mathrm{C}$ instead of $650^{\circ} \mathrm{C}$. Silver-silver-iodide electrodes were prepared by the thermal decomposition, at $450^{\circ}$ to $500^{\circ} \mathrm{C}$, of a paste composed of 90 percent of silver oxide and 10 percent of silver iodide by weight, a method suggested earlier by one of the authors [6]. Bromide-free sodium chloride, potassium chloride, and hydrochloric acid were used for the tests. Sodium bromide was recrystallized three times from water, separated from its saturated solution by a filter of sintered glass, and dried at $200^{\circ}$ to $250^{\circ} \mathrm{C}$ [4]. Other salts were of regeant grade.

The electrodes were brought to equilibrium in the solution of the pure halide, and those which differed from the mean potential by more than 0.1 $\mathrm{mv}$ were rejected. Silver-silver-iodide electrodes often differed by several tenths of a millivolt until hydrogen was bubbled through the solution to remove air.

Each cell was filled with two carefully deaerated portions of the halide solution, to one of which a small quantity of foreign salt (amounting to 0.05 to 0.5 mole per 100 moles of halide) had been added. Each arm was usually filled two or three times and the solution displaced with pure hydrogen before the final filling of the cell. The stopcock was open only while measurements were being made. In one experiment, the stopcock that separated $0.05-M$ hydrochloric acid from a solution $0.05 M$ in hydrochloric acid and 0.000025 $M$ in potassium bromide was left open for 2 days. The constancy of $\Delta E$ during this time indicated that little if any bromide reached the silversilver-chloride electrodes in the pure solution of hydrochloric acid.

The results are summarized in table $1 ; \Delta E$ represents the average difference, in millivolts, between the electrodes in the pure and contaminated halide solutions. In general, $\Delta E$ reached a constant value within an hour. When silver-silver-chloride electrodes were immersed in solutions that contained bromide, or silver-silverbromide electrodes in solutions containing iodide as an impurity, the electromotive force rose slowly for 24 to 48 hours, and sometimes measurement was discontinued before a limit was reached. The lower value of $\Delta E$ in the table usually represents the electromotive force about 1 hour after the cell was filled, and the higher the constant value or that recorded 24 hours later.

TABLE 1.-Effect of small concentrations of foreign salts on the potentials of silver-silver-halide electrodes immersed in solutions of halides at $25^{\circ} \mathrm{C}$

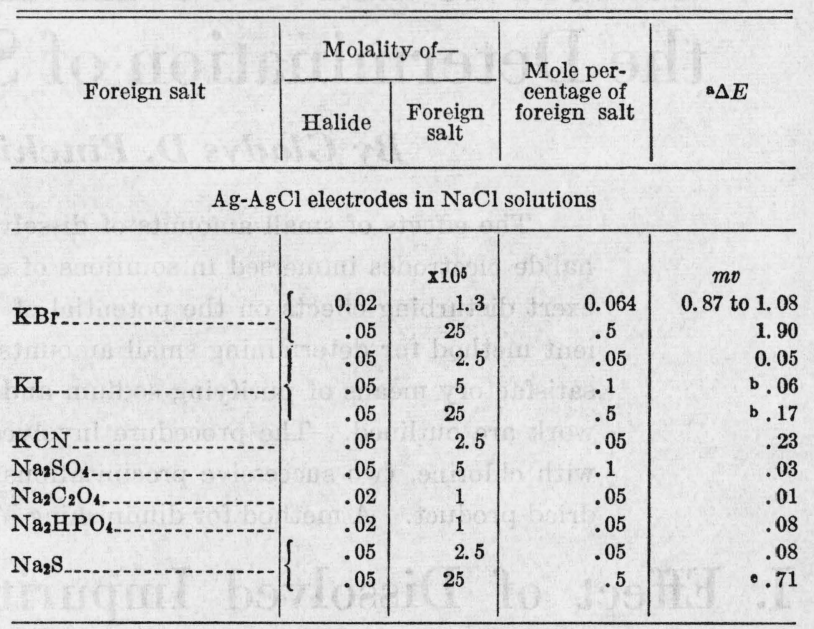

$\mathrm{Ag}-\mathrm{AgCl}$ electrodes in $\mathrm{KCl}$ solutions

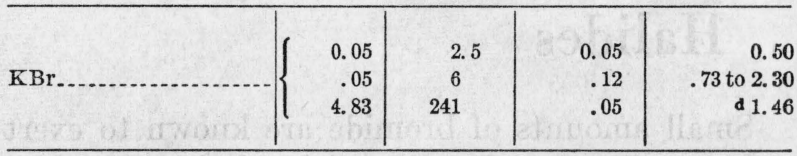

Ag-AgCl electrodes in $\mathrm{HCl}$ solutions

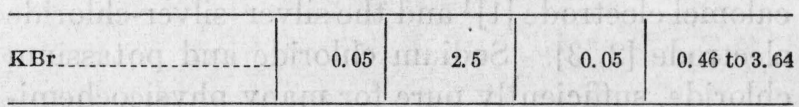

$\mathrm{Ag}-\mathrm{AgBr}$ electrodes in $\mathrm{NaBr}$ solutions

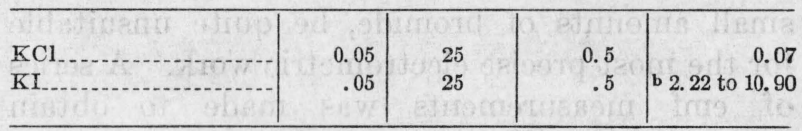

Ag-AgI electrodes in KI solutions

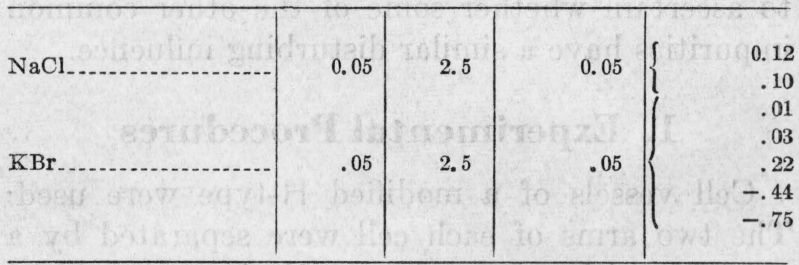

a Positive $\Delta E$ signifies that the electrodes in the solution of impure salt were negative with respect to those in the solution of the pure halide.

b Electrodes in the iodide solution were yellow at the end of the experiment.

- Electrodes in the sulfide solution were black at the end of the experiment.

d Reference [3]. 


\section{Calculation of the Normal Effect of Impurities}

When the impurity forms neither stable complex ions with silver nor compounds less soluble than silver chloride, $\Delta E$ is given by

$$
\Delta E=\frac{R T}{F} \ln \frac{a_{\mathrm{C} 1}}{a_{\mathrm{C} 1}^{\prime}} \pm E_{j},
$$

where $a$ is the activity; $R, T$, and $F$ are the gas constant, the absolute temperature, and the faraday, respectively, and $E_{\mathrm{j}}$ is the potential difference across the liquid junction in the stopcock. As the concentration of chloride ion is the same in both solutions, eq 1 becomes, with the substitution of numerical values for $R, T$, and $F$ at $25^{\circ} \mathrm{C}$ and conversion to the common logarithm,

$$
\Delta E=0.05914 \log \left(f_{\mathrm{cl}} / f_{\mathrm{cl}}^{\prime}\right) \pm E_{j}
$$

where $f$ is the activity coefficient of chloride ion on the molal scale. The difference in the activity coefficient caused by the difference in the ionic strengths of the two solutions can be estimated by use of one of the forms of the Debye-Hückel equation. When 0.5 mole percent of uni-univalent salt has been added to $0.05-m$ sodium chloride, the ionic strength is increased from 0.05 to 0.05025 , and the first term on the right of eq 1 is only 0.01 $\mathrm{mv}$. The value of the liquid-junction potential cannot readily be estimated. In spite of the fact that the solutions on either side of the stopcock are practically identical in composition, $E_{j}$ is possibly large enough to mask the small effect of the change in the activity coefficient.

When certain impurities, such as iodide, are present, even in small concentrations, a silver salt of lower solubility than silver chloride may be formed on the surface of the electrode. From a comparison of the solubility product constants of silver chloride and silver iodide it is easily seen that practically all of the iodide impurity in the immediate vicinity of a silver chloride electrode is replaced by chloride ion, according to the reaction

$$
\mathrm{AgCl}+\mathrm{I}^{-}=\mathrm{AgI}+\mathrm{Cl}^{-} .
$$

In a $0.05-m$ solution of sodium chloride, originally containing $0.00025-\mathrm{m}$ potassium iodide, the concentration of iodide remaining at equilibrium with the electrode is only $10^{-8} \mathrm{~m}$. Thus a concentration cell has been created, with chloride ion in the two arms at molalities of 0.05 and 0.05025 . The emf of such a cell at $25^{\circ} \mathrm{C}$ is given by

$$
\Delta E=\frac{T_{\mathrm{Na}} \Delta \mu_{\mathrm{NaC} !}}{F}=0.1183 T_{\mathrm{Na}} \log \frac{f^{\prime} m^{\prime}}{f m} .
$$

where $\mu$ is the partial molal free energy, or "chemical potential"; $m$ is the molality, and $f$ is the stoichiometrical activity coefficient of sodium chloride; and $T_{\mathrm{Na}}$ is the transference number of sodium ion in $0.05-m$ sodium chloride, found by Longsworth [7] to be 0.388 at $25^{\circ} \mathrm{C}$. From eq 4, the potential of the electrode in the solution to which iodide was added should differ from that of the electrode in the pure solution of sodium chloride by $0.10 \mathrm{mv}$. The electrode immersed in the solution that contained potassium iodide was negative with respect to the other. This computed value agrees satisfactorily with $0.17 \mathrm{mv}$ found by experiment.

The effect of sulfide ions likewise appears to be of this normal type, as 0.05 mole percent of this impurity, considerably more than necessary to exceed the solubility of silver sulfide, produces little if any abnormal effect. When the concentration of sulfide was increased tenfold, however, the electrodes were black in color and were negative to the reference pair by more than half a millivolt. It is possible that the formation of solid solutions is responsible for such a disturbance when deposition of a second silver salt in substantial amounts has occurred. In most cases this phenomenon is of less concern than the more obscure and equally harmful effect of bromide in concentrations insufficient to cause separation of silver bromide.

An accurate computation of the molality of bromide or iodide ion necessary to form solid silver bromide or silver iodide on the surface of a silversilver-chloride electrode immersed in a solution of alkali chloride is perhaps most conveniently made with the aid of the standard potentials, $E^{\circ}$, of the three silver-silver-halide electrodes, namely, $-0.2224(\mathrm{AgCl}),-0.0713(\mathrm{AgBr})$, and +0.1522 $(\mathrm{AgI})$ int. $\mathrm{v}$ at $25^{\circ} \mathrm{C}$. These standard potentials are related to the standard potential of the silver electrode, $E^{\circ}{ }_{\mathrm{Ag}}$, and the solubility product constants, $K_{\mathrm{sp}}$, of the respective silver halides, $\mathrm{AgX}$, by the equation,

$$
\begin{aligned}
E_{\mathrm{Ag} \mathbf{X}}^{\circ}= & E_{\mathbf{A g}}^{\circ}-\frac{R T}{F} \ln K_{\mathrm{gp}(\mathbf{A g X})}= \\
& E_{\mathbf{A g}}^{\circ}-0.05914 \log f_{\mathbf{A g}_{\mathbf{B}}} f_{\mathbf{X}} m_{\mathbf{A g}} m_{\mathbf{X}}
\end{aligned}
$$


When the silver electrode is in equilibrium with a solution saturated with both silver chloride and silver bromide, we have, since $f_{\mathrm{Cl}}$ and $f_{\mathrm{Br}}$ are nearly equal,

$$
E_{\mathrm{AgBr}}^{\circ}-E_{\mathrm{AgCl}}^{\circ}=0.05914 \log \left(m_{\mathrm{Cl}} / m_{\mathrm{Br}}\right) .
$$

In this way, the value of $m_{\mathrm{Br}}$ in equilibrium with solid silver bromide is found to be $0.00279 \mathrm{~m}_{\mathrm{Cl}}$, or 0.28 mole percent of the chloride. Similarly, $m_{\mathrm{I}}=4.63 \times 10^{-7} m_{\mathrm{Cl}}$, or 0.00005 mole percent; and $m_{\mathrm{I}}=0.000166 m_{\mathrm{Br}}$ or 0.017 mole percent.

\section{Anomalous Effect of Bromide on the Silver-Silver-Chloride Electrode}

It can be concluded from table 1 that neither chloride nor bromide exerts a serious disturbing influence on the silver-silver-iodide electrode. Some difficulty was experienced, however, in obtaining reproducible results with iodide electrodes. Because both positive and negative values of $\Delta E$ were obtained, it seems likely that no abnormal effect of bromide exists. Deposition of silver iodide on the silver-silver-bromide electrode caused an abnormal potential difference of $2.2 \mathrm{mv}$, as compared with $0.10 \mathrm{mv}$ calculated in the previous section.

Carmody [8] found that cyanide, absorbed during the electrolytic deposition of silver, was completely removed only after prolonged washing of the electrodes. The residual traces of cyanide effected some reduction of silver chloride during chloridization, and dark electrodes, positive to the white ones by about $0.2 \mathrm{mv}$, resulted. White electrodes were obtained only when the silver was washed for 2 weeks before the silver chloride was formed. As recorded in table 1, electrodes immersed in a $0.05-m$ solution of sodium chloride that contained 0.05 mole percent of potassium cyanide were found to be negative to those in the pure solution of chloride by $0.23 \mathrm{mv}$. The electrodes remained white. It seems likely that the concentration of cyanide in the chloridizing cell would be less than $0.000025 \mathrm{~m}$, the concentration used in the experiment reported in table 1 , when the silvered electrode had been washed for only a few days. Apparently a greater disturbing effect results from the presence of cyanide in small amounts during chloridization of the electrodes than from its presence as an impurity in the solution in which the electrodes are used.

The potential of the silver-silver-chloride electrode is increased by 0.1 to $0.2 \mathrm{mv}$ for each 0.01 mole percent of bromide. In one experiment, the electrodes returned rapidly to substantial agreement when they were replaced in a bromidefree solution of potassium chloride. The cause of the abnormal effect of small amounts of bromide is as yet unexplained.

It has been found [1] that commercial samples of potassium chloride often contain from 0.01 to 0.1 percent of bromide. In view of the magnitude of the error which these amounts would cause, the removal of bromide becomes an important aspect of the purification of salt to be used in precise electrometric work. An investigation was therefore undertaken to find a convenient test for the presence of bromide and to determine an efficient method for removing this impurity. Iodide appears to be absent from most commercial preparations. In view of its relatively small effect on the silver-silver-chloride electrode, special treatment to remove iodide is probably unnecessary.

\section{Determination of Bromide in the Presence of Chloride}

The formation of red eosin (tetrabromofluorescein) by the action of bromine on fluorescein has been utilized for the detection of small amounts of bromide [9]. The modification suggested by Aickin, in which the color was produced on test papers rather than in solution, appeared to be the most convenient. In this method a solution of fluorescein is prepared by stirring the dye in 50percent ethyl alcohol for 30 minutes in the cold and removing the excess by filtration. Strips of filter paper are dipped into the solution, allowed to dry, and stored in the dark until needed. Two- tenths milliliter of a saturated aqueous solution of the salt to be tested is placed in a small test tube (about $1 \times 7.5 \mathrm{~cm}$ ) with an equal volume of a 25-percent solution of chromic acid. A piece of test paper, moistened with water, is placed on the top of the tube, which is then heated in a water bath for 5 minutes.

When the method was employed in this laboratory, however, no consistent results could be obtained. A large number of tests were consequently made in which all of the conditions were varied, singly and in combination. Test papers 
that had been allowed to dry and remoistened with water were unreliable. It was found necessary to dip the filter paper into the dye solution immediately before use. Further, conditions of the test had to be redetermined each day when tests were begun, in order to obtain satisfactory results.

To estimate small amounts of bromide, conditions were adjusted until a barely discernible pink color was produced by 0.001 mole percent, and a fairly bright pink by 0.005 . These conditions varied within wide limits. For example, the time of heating necessary to produce satisfactory colors from day to day varied from $1 \frac{1}{2}$ to 15 minutes, and the concentration of the chromic acid solution had to be varied from 25 percent to a saturated solution. The dye solution was sometimes used as prepared, and sometimes had to be diluted as much as eightfold to obtain the desired color. These changes appeared to be made necessary by changes in the fluorescein solution effected by -precipitation of fluorescein and by evaporation of the solvent. Even the freshly prepared dye solutions appeared to differ somewhat, possibly because of slight differences in the proportion of alcohol to water and in the temperature at which the solution was saturated.

By replacing fluorescein with its sodium salt, uranine, the most time-consuming steps of this procedure were eliminated. As the salt is readily soluble in water, preparation of the dye solution was considerably simplified. It was necessary only to dissolve sufficient uranine in water to make a solution containing approximately 0.05 percent of the salt by weight. Solutions stored in the laboratory for a month gave satisfactory results. The stability of the dye solution made the daily adjustment of test conditions unnecessary, and it was then possible to establish a definite procedure that yielded consistent results.

The modified procedure for the bromide test was as follows: Two-tenths milliliter of saturated chromic acid solution was added to an equal volume of a saturated solution of the salt to be tested. A circular piece of filter paper was dipped into the uranine solution and placed over the mouth of the test tube. A rack constructed of copper sheet and No. 10 copper wire, shown in figure 1, was found convenient for making several tests simultaneously. The rack holds six tubes and fits into a $250-\mathrm{ml}$ beaker. The tubes were heated in boiling water for 6 minutes. Comparison solutions containing known amounts of bromide should be included with each set of unknown solutions tested. For very small amounts of bromide, when visual comparison is difficult, colors of the test papers can often be compared to advantage under ultraviolet light. One-thousandth mole percent can be detected, and the test is accurate to about \pm 0.002 mole percent.

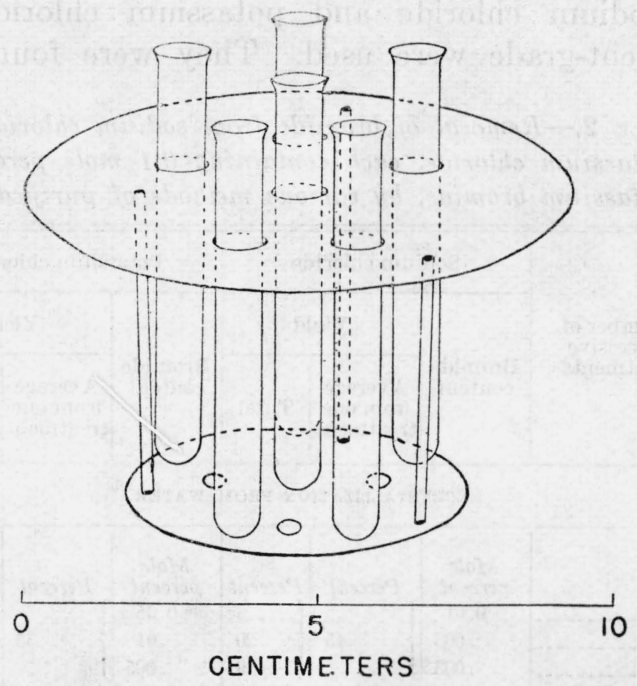

FIGURE 1.-Copper rack used for supporting small test tubes in boiling water for the bromide test.

This test can be adapted to the determination of larger amounts of bromide by increasing the concentration of the dye solution, decreasing that of the chromic acid solution, decreasing the time, or by diluting the solution to be tested. The last procedure is the most accurate. Because many organic materials, if present in sufficient amount, may react explosively with chromic acid, it is advisable to perform the test on the semimicroscale as described above. 


\section{Methods of Purifying Sodium Chloride and Potassium Chloride}

Four methods commonly used in purifying sodium and potassium chlorides for electrochemical work, namely, recrystallization from water, precipitation with ethyl alcohol $[1,10]$, precipitation with hydrogen chloride gas [11], and treatment with chlorine [12], were investigated to determine which was the most effective for removing bromide and for obtaining a satisfactory yield. On the basis of these results, a combination of methods was selected to prepare, in satisfactory yield, sodium and potassium chlorides free from bromide and other impurities.

Sodium chloride and potassium chloride of reagent-grade were used. They were found to

TABLE 2.- Removal of bromide from sodium chloride and potassium chloride, each containing 0.1 mole percent of potassium bromide, by various methods of purification

\begin{tabular}{|c|c|c|c|c|c|c|}
\hline \multirow{3}{*}{$\begin{array}{l}\text { Number of } \\
\text { successive } \\
\text { treatments }\end{array}$} & \multicolumn{3}{|c|}{ Sodium chloride } & \multicolumn{3}{|c|}{ Potassium chloride } \\
\hline & \multirow[b]{2}{*}{$\begin{array}{l}\text { Bromide } \\
\text { content }\end{array}$} & \multicolumn{2}{|c|}{ Yield } & \multirow[b]{2}{*}{$\begin{array}{l}\text { Bromide } \\
\text { content }\end{array}$} & \multicolumn{2}{|c|}{ Yield } \\
\hline & & $\begin{array}{l}\text { Average } \\
\text { from one } \\
\text { treatment }\end{array}$ & Total & & $\begin{array}{c}\text { Average } \\
\text { from one } \\
\text { treatment }\end{array}$ & Total \\
\hline
\end{tabular}

RECRYSTALLIZATION FROM WATER

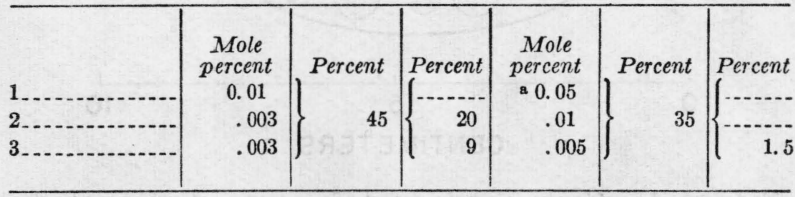

PRECIPITATION WITH ALCOHOL

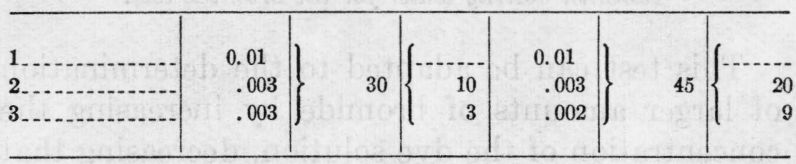

PRECIPITATION WITH $\mathrm{HCl}$

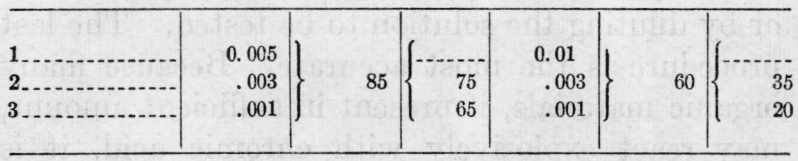

TREATMENT WITH $\mathrm{Cl}_{2}$, CRYSTALLIZATION FROM WATER

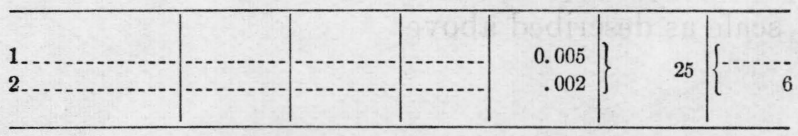

TREATMENT WITH $\mathrm{Cl}_{2}$, PRECIPITATION WITH $\mathrm{HCl}$

\begin{tabular}{|c|c|c|c|c|c|c|}
\hline $1 \ldots \ldots$ & 0.001 & 85 & 85 & 0.001 & 60 & 60 \\
\hline
\end{tabular}

a Approximate figure. contain initially 0.001 and 0.05 mole percent of bromide, respectively. Sufficient potassium bromide was added to the filtered solution of each salt to be purified to make the bromide content 0.1 mole percent. Pyrex-glass vessels were used for all of the tests except the fusions. The bromide content of the products and the yields obtainable by the different methods are shown in table 2 .

\section{Recrystallization From Water}

Potassium chlorida was recrystallized three times from water. In the first crystallization, the following three fractions were taken: One by cooling the saturated solution from $100^{\circ}$ to $25^{\circ} \mathrm{C}$, a second by cooling from $25^{\circ}$ to $6^{\circ} \mathrm{C}$, and a third by evaporating the filtrate to about six-tenths of its volume and cooling to $6^{\circ} \mathrm{C}$. The products represented 25,13 , and 27 percent, respectively of the original material. All three contained rather large amounts of bromide, in excess of 0.01 mole percent. The first contained less than the second, and the second less than the third. The second and third fractions were discarded. In the subsequent recrystallizations a single fraction was taken by cooling the saturated solution to $25^{\circ} \mathrm{C}$. Sodium chloride was recrystallized three times by evaporating a solution saturated at the boiling temperature to six-tenths of its volume and cooling to $6^{\circ} \mathrm{C}$.

\section{Precipitation With Ethyl Alcohol}

Potassium chloride was purified by three successive precipitations from a saturated aqueous solution at room temperature by the addition of an equal volume of ethyl alcohol. By adding the saturated salt solution dropwise to the alcohol, with stirring, the yield from each precipitation was increased from 35 to 45 percent. Sodium chloride was also purifiad by this latter procedure.

\section{Precipitation With Hydrogen Chloride}

Hydrogen chloride gas, generated by dropping concentrated hydrochloric acid into concentrated sulfuric acid, was passed into saturated solutions of sodium and potassium chlorides through an inverted glass funnel. The precipitated salt was 
collected on a sintered glass filter, washed with small portions of water, and dried at $110^{\circ} \mathrm{C}$. Three successive precipitations were made. When an acidified solution of the product was tested by addition of barium chloride solution, no sulfate was detected.

\section{Treatment With Chlorine}

Chlorine was passed into a saturated solution of potassium chloride for about 10 minutes. The solution was boiled to remove chlorine and bromine and brought to saturation at the boiling temperature. The salt was recrystallized by cooling the solution to $25^{\circ} \mathrm{C}$, and a second recrystallization from water was made. The $\mathrm{pH}$ of the solution saturated with chlorine was found by glass-electrode measurement to be 2.2. An acidified sample of the purified salt was tested by the addition of potassium iodide and starch solution, and the mixture remained colorless.

\section{Detection and Removal of Iodide}

Although iodide is not commonly found in reagent-grade chlorides in appreciable amounts, it was thought desirable to determine whether iodide, if present, would be removed by the method found most satisfactory for the removal of bromide. The test used for bromide was not adaptable to the detection of iodide, probably because of the lower volatility of iodine. Although iodine substitutes in fluorescein to form coral-pink erythrosin, the test did not appear to be sufficiently sensitive. One-tenth mole percent was required to produce a color on fluorescein paper, and almost 1 mole percent was needed when uranine was used. The salts were tested for iodide [13] by acidifying $6 \mathrm{ml}$ of the saturated solution with 10 drops of $5-M$ hydrochloric acid, oxidizing the iodide, if present, with 2 drops of 3 -percent hydrogen peroxide, and extracting the iodine with $6 \mathrm{ml}$ of chloroform or carbon tetrachloride. One-thousandth mole percent of iodide produces a pale but discernible lavender color.

One-hundredth mole percent of potassium iodide was added to saturated solutions of sodium and potassium chlorides which also contained 0.1 mole percent potassium bromide. Tests for iodide in the salts obtained by precipitation with hydrogen chloride after treatment of their saturated solutions with chlorine were negative.

\section{Fusion of Sodium Chloride and Potassium Chloride}

The most satisfactory means of removing hydrochloric acid from sodium or potassium chloride precipitated in a strong solution of the acid is to heat the salt to fusion. The fused salt is not only free of occluded acid but is completely dry, a condition often difficult to achieve at temperatures below the melting point [14]. Unfortunately, this treatment usually yields a slightly alkaline product. The total alkalinity amounted in several experiments to 0.001 to 0.01 mole per 100 moles of salt. Sodium chloride is normally considerably more alkaline after fusion than potassium chloride treated similarly.

Johnson [15] concluded that the alkali is formed by a reaction of the vapor of the chloride with atmospheric moisture. He found that the alkalinity of sodium chloride could be reduced to 0.0001 mole percent by drying the salt at $180^{\circ} \mathrm{C}$ and fusing in an atmosphere of dry nitrogen. Lux [16] showed that sodium chloride and potassium chloride become alkaline when heated at $600^{\circ} \mathrm{C}$, or considerably below their melting points.
Bjerrum and Unmack [17] titrated solutions of fused sodium chloride and potassium chloride with acid and found that the salts contained 0.003 and 0.001 mole percent, respectively, of free alkali. When Johnson fused sodium chloride in moist air, a product containing 0.005 mole percent of sodium hydroxide was obtained. On the contrary, Richards and Wells [18] state, "The salt remained strictly neutral after fusion in a vacuum, as it did in air." Because Richards and Wells fused samples of dry salt in an apparatus from which moisture would have been expelled during the early stages of heating, this observation is not at variance with the findings of Johnson.

The molten chlorides wet the surfaces of platinum boats and crucibles and adhere to the vessels on solidifying. Consequently, it is necessary to pour the fused salt into another platinum container whose temperature is sufficiently low so that the salt does not stick tightly. Protecting the hot salt from moist air under these conditions is obviously difficult. 
The arrangement shown in figure 2 was found to be quite effective in reducing the hydrolysis of sodium and potassium chlorides during fusion. The 40-ml platinum crucible, $B$, fits loosely into the clear quartz tube, $A$, which is $11 \mathrm{~cm}$ long and $43 \mathrm{~mm}$ in diameter. Platinum foil, $0.005 \mathrm{in}$. thick, was used to form the trough, $C$. The foil was cut and folded to form the dam at the upper end. The Pyrex cover, $D$, fits snugly over the quartz tube but is loose enough to permit the dry nitrogen or air entering at the top to escape. Asbestos paper was wrapped around the quartz tube to permit the apparatus to be supported easily in the top of a crucible furnace with an opening $5 \mathrm{~cm}$ in diameter.
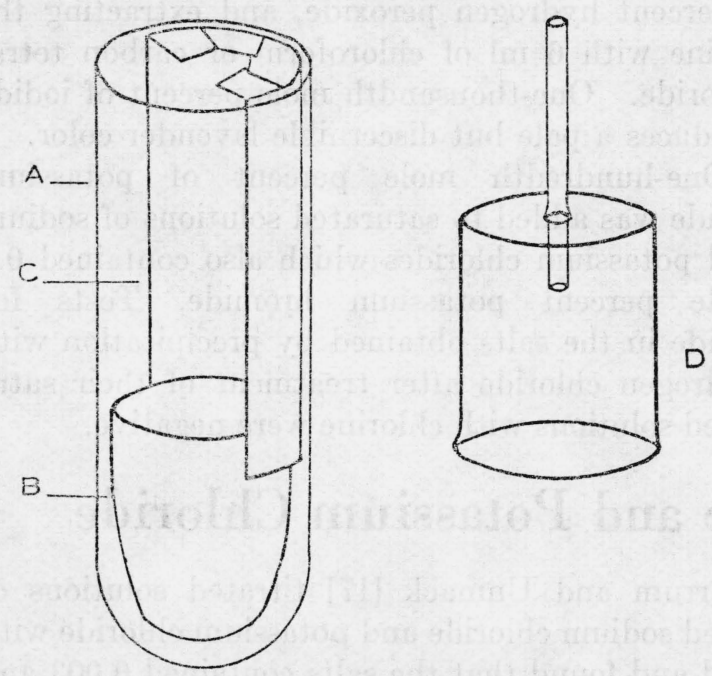

FIGURE 2.-Apparatus for diminishing hydrolysis of sodium and potassium chlorides during fusion.

$A$, Clear quartz tube; $B$, platinum crucible; $C$, platinum trough; $D$, glass cover.
The crucible was charged with about $20 \mathrm{~g}$ of salt that had been ground in an agate mortar and dried at $180^{\circ} \mathrm{C}$. The cover was wired in place, a slow stream of dry nitrogen passed for 5 minutes to replace all of the moisture-laden air, and the tube finally supported in the top of the furnace maintained at $1,000^{\circ} \mathrm{C}$. The salt was usually completely melted in 10 to 15 minutes. When all the salt had fused, the tube was withdrawn from the furnace, tipped to allow the molten salt to flow into the cooler trough, and placed on its side to cool with the nitrogen still flowing.

By this procedure, neutral sodium and potassium chlorides can be fused without introducing more than 0.001 mole percent of free alkali. Indeed, sodium chloride dried at $180^{\circ} \mathrm{C}$ could usually be fused in this apparatus without the use of dry nitrogen, with satisfactory results. It appears that moisture was expelled from the tube before fusion took place and did not enter again until the melt had solidified and partially cooled. Because its tendency toward hydrolysis at elevated temperatures is less marked than that of sodium chloride, the potassium salt will usually contain after fusion no more than 0.003 mole percent of free alkali, even though it be fused in an open crucible exposed to atmospheric moisture. When the apparatus shown in figure 2 is used, however, the salts are nearly neutral.

The alkalinity of the chlorides was determined by titrating 5 - to $12-\mathrm{g}$ samples of fused salt with a $0.01-M$ solution of hydrochloric acid. Bromthymol blue was used as the indicator, and the endpoint was established by comparison with a color standard prepared from the indicator and a phosphate buffer of pH 7 [19].

\section{Recommended Procedures}

For use in precise electrometric work with the calomel or silver-silver-chloride electrodes, sodium chloride and potassium chloride should not contain more than 0.005 mole percent of bromide. If the accuracy of the measurement is expected to approach $0.02 \mathrm{mv}$, the quantity of bromide must be no greater than 0.002 mole percent. If, further, the salts are to be employed in $\mathrm{pH}$ work in conjunction with electrodes reversible to hydrogen (or hydroxyl) ion, the neutrality of the salt must be assured. It is likewise necessary that the pro- cedure for drying the salt shall yield a product that is known to be moisture free.

The requirements of electrometric $\mathrm{pH}$ work are, therefore, somewhat different from those of other types of physicochemical investigations. In purification procedures, the emphasis must be placed upon achieving a neutral salt free from bromide. Other inert impurities need receive only secondary consideration.

Precipitation with hydrogen chloride was found by Richards and Wells [18] to be the best method 
of purifying sodium chloride. A commerical preparation of the salt subjected to three precipitations gave a product with the same combining weight as other samples prepared by several other more elaborate procedures. As shown in the preceding sections, about 98 percent of the bromide can be removed from a saturated solution of sodium chloride by a single treatment with chlorine and one precipitation with hydrogen chloride. It can be concluded from the work of Richards and Wells that two successive precipitations would reduce the amounts of other impurities to the negligible level. They also found that the salt did not pick up moisture during weighing in dry winter air. The fused salt can, however, be fractured and weighed in large lumps to minimize its tendency to adsorb moisture from humid atmospheres.

The treatment with chlorine and precipitation with hydrogen chloride is apparently effective for removing bromide and iodide from potassium chloride, as well as from the sodium salt. The investigation described by Richards [20] is undoubtedly the most detailed and most carefully executed study of the removal of the other impurities from the salt. In order to remove substances isomorphous with potassium chloride, Richards subjected commercial potassium nitrate to repeated recrystallization. The nitrate was then converted to chloride which was, in turn, further purified by precipitation with hydrogen chloride. As the elimination of small amounts of other alkali halides from sodium chloride was readily effected by precipitation with hydrogen chloride [18], it seems reasonable to assume that they would be similarly removed from potassium chloride. Other isomorphous impurities normally are present in extremely small amounts.

In the light of these considerations, it can be concluded that the same procedure will serve to prepare sodium chloride and potassium chloride with less than 0.002 mole percent of bromide and free of iodide and significant amounts of inert impurities.

Chlorine is bubbled for 10 minutes at a moderate rate through a filtered solution of the salt, saturated at room temperature. The solution is then boiled for 5 minutes to remove free halogens. The salt is precipitated twice with hydrogen chloride from a solution saturated at room temperature, collected on a filter, preferably of sintered glass, washed with small portions of pure water, and dried at $180^{\circ} \mathrm{C}$. Finally, the salt is fused, as described in the previous section, to remove occluded water and hydrochloric acid. These preparations should meet the most exacting requirements of electrochemical work.

\section{References}

[1] F. L. Hahn, J. Am. Chem. Soc. 57, 2537 (1935).

[2] E. Güntelberg, Studier over Elektrolyt-Aktiviteter. G. E. C. Gads Forlag, Købnhavn. (Dissertation, 1938.)

[3] G. G. Manov, N. J. DeLollis, and S. F. Acree, J. Research NBS 34, 115 (1945) RP1632.

[4] H. S. Harned, J. Am. Chem. Soc. 51, 416 (1929).

[5] A. S. Keston, J. Am. Chem. Soc. 57, 1671 (1935).

[6] R. G. Bates, J. Am. Chem. Soc. 60, 2983 (1938).

[7] L. G. Longsworth, J. Am. Chem. Soc. 54, 2741 (1932).

[8] W. R. Carmody, J. Am. Chem. Soc. 51, 2901 (1929).

[9] H. Baubigny, Compt. rend. 125, 654 (1897); A. Labat, Bul. soc. chim. [4] 9, 393 (1911); R. Lorenz, E. Grau, and E. Bergheimer, Z. anorg. Chem. 136, 90 (1924); F. L. Hahn, Compt. rend. 197, 245 (1933); R. G. Aickin, Australian Chem. Inst. J. \& Proc. 4, 267 (1937).

[10] B. Saxton and T. W. Langer, J. Am. Chem. Soc. 55, 3638 (1933).

[11] T. Shedlovsky, J. Am. Chem. Soc. 54, 1411 (1932).
[12] G. G. Manov, N. J. DeLollis, and S. F. Acree, J. Research NBS 33, 287 (1944) RP1609.

[13] J. von Mik6, Arch. Pharm. 265, 445 (1927); Pharm. Zentralhalle 1927, 763.

[14] T. W. Richards, Z. physik. Chem. 46, 189 (1903).

[15] C. R. Johnson, J. Phys. Chem. 39, 791 (1935).

[16] H. Lux, Z. Elektrochem. 48, 210 (1942).

[17] N. Bjerrum and A. Unmack, Kgl. Danske Videnskab. Selskab., Math.-fys. Medd. 9, 1 (1929).

[18] T. W. Richards and R. C. Wells, A revision of the atomic weights of sodium and chlorine, Carnegie Institution of Washington (1905).

[19] R. G. Bates and S. F. Acree, J. Research NBS 34, 373 (1945) RP1648.

[20] T. W. Richards, Further researches concerning atomic weights of potassium, silver, chlorine, bromine, nitrogen, and sulphur; Carnegie Institution of Washington (1907).

Washington, June 10, 1946. 